\title{
IMPROVING THE PRODUCTIVITY AND THE WORK ENVIRONMENT FOR MODIFYING A HAMMER MILL THRESHER
}

\author{
E. A. El Saeidy*
}

ABSTRACT

There have been extensive researches on improving the productivity, the efficiency and the power requirement for milling machines. However less or maybe there is no effort were done to improve the work environment. On the other hand, most of the agricultural machines are seasonal machines for only one operation. This raises the cost of this operation to cover the investment in the machine. In addition, the machine exposed to some damages like rust if it is not well maintained.

A hammer mill machine was modified to mill a wide range of farm residuals. The aim of this work is to improve the operating environment by reducing the machine sound level. That will be the main target of this work. An added value to this machine will be done also by using it to mill poultry fodder after modified it. That will be another target of this work.

Keywords: Threshing machines, Hammer, Farm residuals, environment.

\section{INTRODUCTION}

$\mathrm{I}$ f poultry are expected to remain healthy and productive, it must consume adequate amounts of all the necessary nutrients. The quantity of each required nutrient varies depending on many variables like species of bird, age, productive state, environmental conditions and disease status. In the most Egyptian villages and in the popular areas the housewives are breeding poultry. The fodder consists mainly of threshing maize, hacking clover and food residuals. They buy the maize with cob, overcook and threshing it. So, small threshing stores are widely distributed in Egypt in these zones. It is usually a small store in a house in residential area. The noisy produced from the threshing usually over limit. The noisy limits in the residential areas of the cities in law 4 for year 1994 of the Egyptian Ministry of Environment ranged between 45-55 decibels. Its range is between 35 and 45 decibels in the rural residential areas (EEAA, 1994).

*Lecturer of Agric. Eng., Dept. of Agric. Eng., Fac. of Agric., Menoufia Univ. Egypt. 
Ajaka and Adesina (2014) mentioned that there are various types of machines used for size reduction of materials. The hammer mill is the most widely used because of its desirable characteristics which include ability to handle a wide variety of raw materials, ability to handle hard stray objects and its robustness.

Adekomaya and Samuel (2014) said that a conventional hammer mill is a device consisting of a rotating head with free swinging hammers, which reduce rock, grain or similarly hard objects to small size throughout a perforated screen, hammer mills can be used mill grains for animal feed production.

Jihoe et al. (2014) added that the hammer mill is an impact type crusher, is one of the most extensively used mills for crushing and it provides high performance breakage. A hammer mill provides a high size reduction ratio i.e., that ratio of the particle size of the feed to that of the product by just a single stage of braking, without having stepwise operations or using different types of grinding equipment's for each stage. Another advantageous is that its throughput per time is very high.

Tingshuang et al (2002) reported that, the advantages of the hammer mill are its high productivity, wide application and fine particle output. Hammer mills grind material by the impact of high-speed rotary hammers. They are either tangential or axial-feed types according to their structure. It can be used to mill cereals, green grass and various straws with high moisture and fiber content. In this case it called a "grass powder miller." However, its energy consumption is high.

Abdel Mottaleb and Obaia (2006) tested and evaluated a hammer mill machine for milling date palm leaves. The machine was used at different milling speeds, different leaf moisture contents and different concave hole diameters to assess the machine productivity, efficiency, energy requirements and fineness degree. The results showed that the optimum machine performance was obtained at $4.8 \%$ leaves moisture content, 1200 rpm drum speed and $22 \mathrm{~mm}$ concave whole diameter.

Hegazy (2006) developed and evaluated a grain crusher of local make. The results revealed that the optimum operating conditions were obtained at $44.21 \mathrm{~m} / \mathrm{s}$ hammer speed and $22.5^{\circ}$ of hammer edge angle. At these levels maximum crusher productivity of 0.228 ton and lowest power 
requirement of $3.521 \mathrm{~kW}$ and energy consumption $2.447 \mathrm{~kW}$.h/ton were obtained.

Egela et al. (2003) found that, the hammer mill feed opening and the speed of the machine rotor shaft were the most significant factors affecting energy requirements.

Yousef (2005) added that, the power requirements of the grinding operation increased with increasing feed rates and it decreased with increasing screen opening size.

El Shal et al. (2010) said that, nowadays, the development of animal and poultry production needs to exert more efforts to increase and maintain high levels of feeding crop, in addition to improve the quality and quantity by decreasing grain losses during pre- processing operation, selecting the proper diet in the acceptable phase of livestock and reducing the consumed energy. The hammer mill is used almost exclusively in preparation of broiler rations because of its simplicity, ease to operate and low maintenance cost so, it had been widely spread in most of the poultry farms in Egypt.

Hegazy et al. (2002) indicated that increasing hammer revolving speeds from 1000 to $2500 \mathrm{rpm}$ ( 16.6 to $41.5 \mathrm{~m} / \mathrm{s}$ ) cause a corresponding increase in the machine productivity.

As an added value for the modified machine in this work, it will be used for a new process as a threshing machine. In addition to that, its features as environmentally friendly machine will be studied.

\section{MATERIALS AND METHODS}

This work was done in the workshop of Department of Agriculture Engineering, Faculty of Agriculture, Menoufia University. A modified hammer mill machine for milling farm residual was used to thresh the fodder cereals. This process will improve the machine category as a multi propose machine.

The objectives of this study are: -

1- Good investment because of the high income from the machine.

2- Protecting the machine from rust, correction and erosion because of storing. 
3- Improving the work environment by reducing the machine noisy to the legal limits specially it works in residential zone.

To achieve these objectives these procedures was followed.

1- Fodder Maize was milled in the machine using $0.5 \mathrm{~cm}$ sieves.

2- The hammer modified to reduce the machine noisy.

3- Measuring the machine noisy before and after the hammers modification.

\section{Technical specification of the machine}

The machine was manufacturer in year 2011 by El-Delta

Company for Agricultural machines, Eknaway, Tanta, Ghrbiaya Governorate. Its parts and specifications are as follow.

\section{Milling room}

Steel Sheet (steel 37)

\section{Rotor shaft}
Material:
Steel 50
Diameter:
$40 \mathrm{~mm}$
Length:
$450 \mathrm{~mm}$

\section{Blades}

Type:

Hammers

Material: percentage
Length:
$130 \mathrm{~mm}$
Width: $40 \mathrm{~mm}$
Thickness: $5 \mathrm{~mm}$
Blade angle:
35 degree

The experimental work starts first with the original blades. These blades were single blades and constructed on the submain shaft. A circular clearance of $3 \mathrm{~mm}$ found between the blades and the shaft Fig .1.

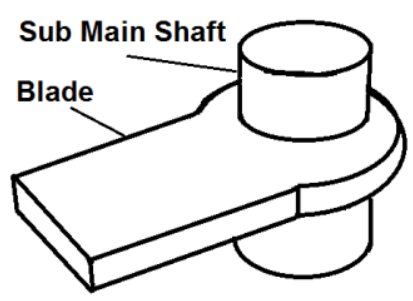

Fig. 1. Original blades 
As a modification, the blades were constructed in two shapes. One is a blade welded in the middle of the steel sleeve and constructed in the submain shafts. Its number is 4 blades per shaft and totally 8 blades in the machine. The other is the blades were welded in the sleeve edges and constructed in the next shaft. This makes the blades don't interact with each other and make noisy. The circular clearance reduced to $1 \mathrm{~mm}$ as an attempt to fix it to the shaft to reduce the noisy. This double blade sleeves are 4 sleeves. It constructed in the submain shafts and the total number of 8. These modified blades are presented in Figs. 2 and 3.

The environmentally friendly modification was done with the same procedures as the presented before, only wide steel sleeves were used to weld blades on it.

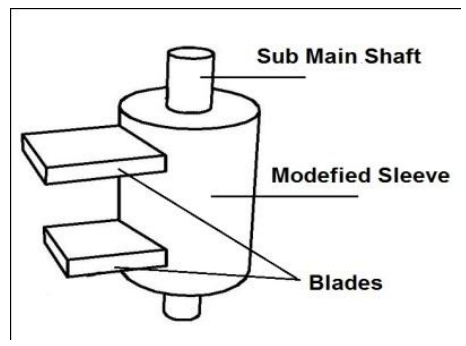

Fig. 2. The Modifies blades

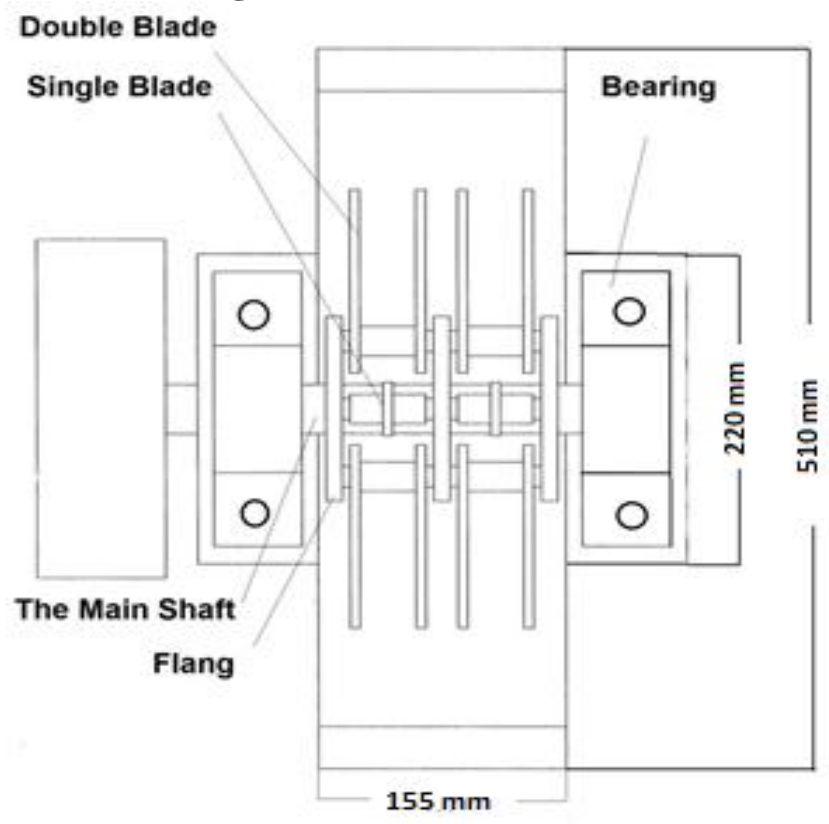

Fig. 3. The Modifies blades 
Hard plastic sleeves were settled up fix between the sub axial shaft and the steel sleeves of the blades as shown in Fig. 4. In addition, the circular saw disks were also constructed on the sub axial shaft.

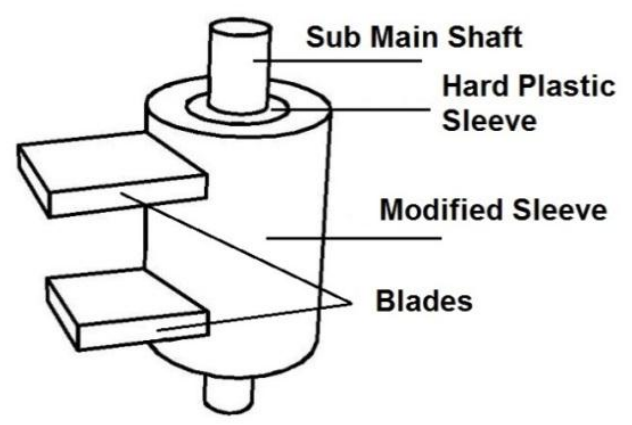

Fig. 4. The modified blade with hard plastic sleeves

\section{The plastic sleeves}

The plastic sleeves were set up to be as between the blades and the shaft. It made from hard plastic which resist the friction and the heat. The clearance between the blades makes a lot of noisy especially with high speed. It makes erosion also in blade sleeve. The main propose of using this sleeve is to reduce the noisy. The different between the sub main shafts before and after hard plastic sleeves constriction is presented in Fig. 5.

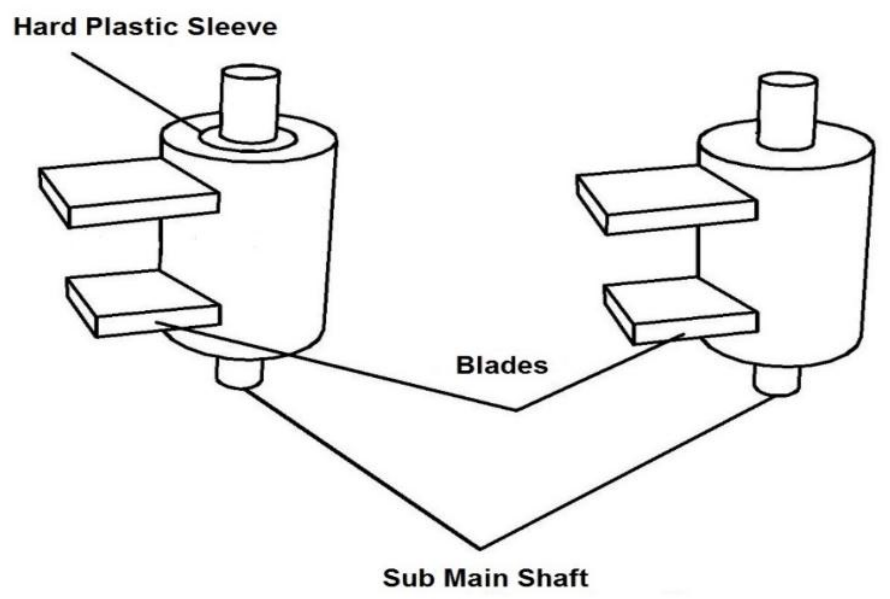

Fig. 5. The different between the sub main shafts before and after hard plastic sleeves constriction 
Flanges

No. of flanges: $\quad 2$

Diameter: $\quad 150 \mathrm{~mm}$

Thickness: $\quad 10 \mathrm{~mm}$

\section{The machine axial main shaft}

The machine has an axial main shaft connected with two flanges and mounted by ball bearing. It is $40 \mathrm{~mm}$ diameter (St. 50). The assembly is bolted to the mill frame for easy removal and repair as shown in Fig.6.

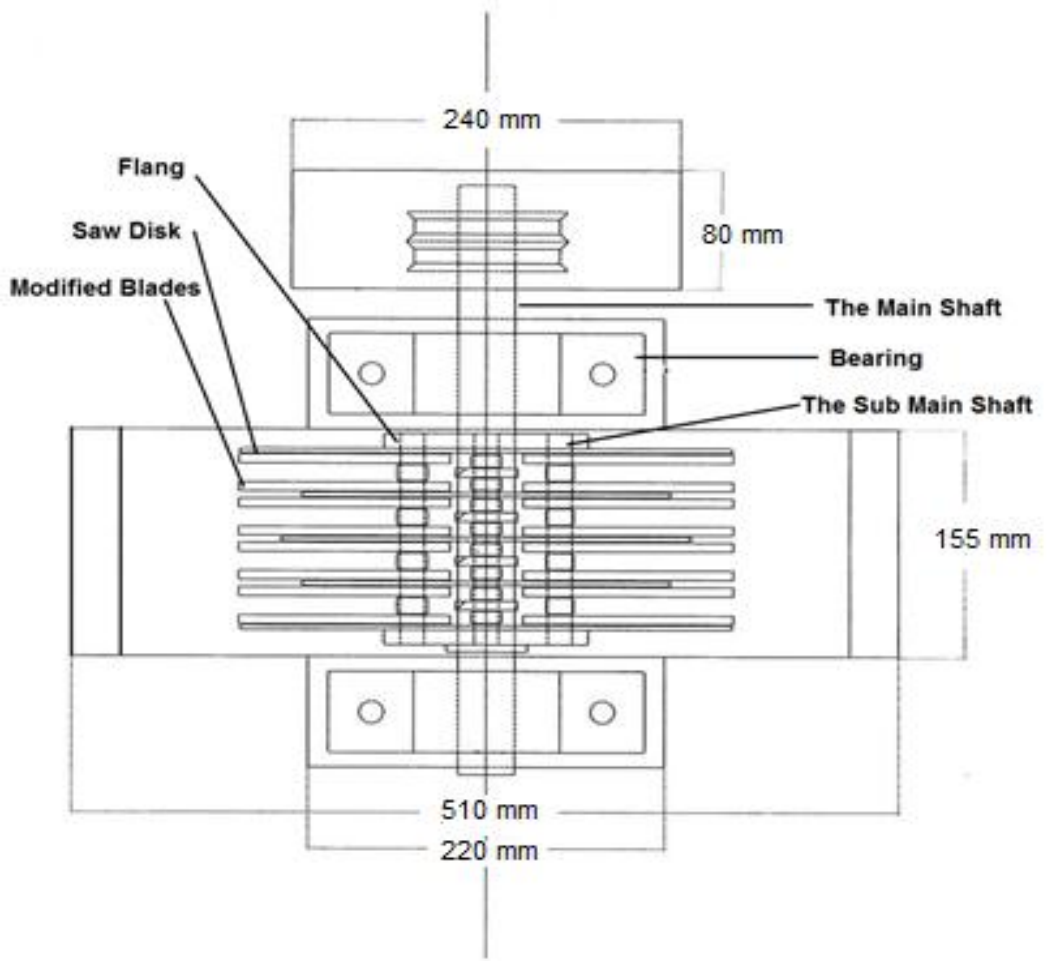

Fig. 6. The plane of the modified machine shows blade, main and sub main shaft mounted on the bearing.

\section{The sub main shafts}

Four sub main shafts of $15 \mathrm{~mm}$ diameter and $143 \mathrm{~mm}$ length (St. 42) were constructed to mount the blades and to connect the flanges. The saw disk blades were also connected to this shaft. The blades were set up on the shafts. To fix the blades on the shafts a hard plastic sleeves were but between the blades and the sub main shaft as shown in Fig. 6 . 
Sound Level Meter.

To measure the noisy of the machine, a sound level meter presented in Fig. 7 was used for this process. Its technical data are followed:

Model

Measuring range

Company

Center Drive.
: Quest Models 2200.

: 30-140 db.

: Quest Technologies, 1060 Corporate Wisconsin, 53066 USA.

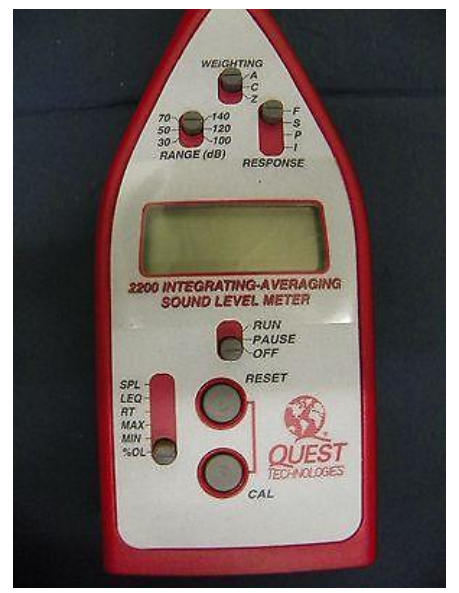

Fig. 7. Quest Sound Level Meter

\section{The motor}

The motor used to drive the machine has the following specifications:

Type : Single phase electric motor

Power : $1.5 \mathrm{~kW}$ Volt: $220 \mathrm{~V}$

The motion was transmitted from the Motor to the main shaft by using a pulley and a V-belt.

\section{Hammer mill Velocity}

The Hammer mill velocity at drum rotational speed about $2200 \mathrm{rpm}$ was $(34.54 \mathrm{~m} / \mathrm{s})$. A digital hand tachometer was used to measure the speed of the axial shaft. It gives the revolution in (r.p.m).

\section{Circular saw disk}

It is a power-saw using a toothed disc or blade to cut different materials using a rotary. The advantage of these disks that when cut it produces minimal burr, no sparks and no dust. Fig. 8 shows the saw disk. 
Five disks were used in the machines, 2 of $30 \mathrm{~cm}$ diameter, 2 of $22.5 \mathrm{~cm}$ diameter, and one of $25 \mathrm{~cm}$ diameters). They were arranged in a way that helps to prevent clogging the machine. They were fixed to the main shaft by a key.

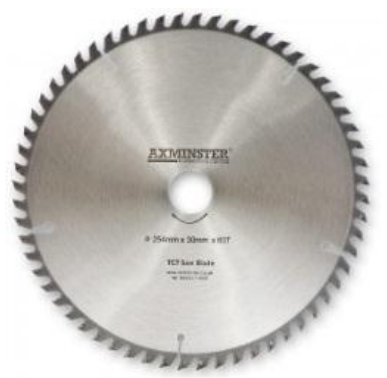

Fig. 8. The circular saw disk

\section{Sieve}

Most of the Egyptian housewife's in the cities or in the rural areas who breeding poultry buy the chicken in the edge of maximum 1 week. This need a very fine threshed maize. For this reason, a sieve with holes' diameter of $0.5 \mathrm{~cm}$ as shown in Fig. 9 was used in this work. It was made of steel (St.37). The clearance between knives and machine concave was $1 \mathrm{~cm}$.

The Maize grains are disintegrated because of the impact action of the hammers and the sawing action of the circular saw disks. It passes through the screen which gives the desired diameter.

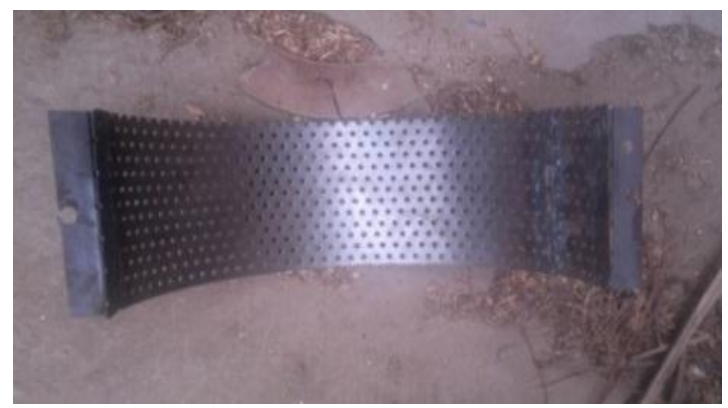

Fig. 9. The Sieve

\section{RESULTS AND DESECUSSIONS}

The experiments were done to evaluate the machine performance at every stage of the blades modification. In addition, the effect of these modifications on the machine sound was also studied. 


\section{1 - The Effect of the blade construction on the machine productivity 1.1 The Primary feeding rate}

By the primary feeding rate, the machine productivity was $674.5 \mathrm{Kg} / \mathrm{h}$ when using the original blades. As presented in Fig. 10 the machine productivity increased by about $17.6 \%$ by using the modified blades and it increased another one to $12.7 \%$ when using the modified blades with the circular disks to reach $864 \mathrm{Kg} / \mathrm{h}$. That means, using the modified blades with the circular saw disks increased the machine productivity with about $28 \%$ than using the original blades.

\subsection{Increasing the feeding rate by 50 percent}

Increasing the feeding rate by $50 \%$ than the primary feeding rate increased the machine productivity about $21.4 \%$ for the original blades to reach $819 \mathrm{Kg} / \mathrm{h}$. Using the modified blades in this case increased the machine productivity with $26,6 \%$ than the similar process with the primary feeding rate to reach $970.85 \mathrm{Kg} / \mathrm{h}$. This increase was $30.66 \%$ for the modified blades with the circular saw disks compared with the primary feeding rate.

The machine productivity increased about $18.5 \%$ by using the modified blades than the original blades. It increased another one $16.3 \%$ when using the modified blades with the circular disks than the modified blades. That means, using the modified blades with the circular saw disks increased the machine productivity with about $37.8 \%$ than using the original blades as in Fig. 10.

\subsection{Increasing the feeding rate by 100 percent}

The results of this stage seem to be different than expected. Increasing the machine feeding rate $100 \%$ decreased generally the machine productivity. The machine productivity decreased about $32.5 \%$ for using the original blades than by the primary feeding rate. This decrease was $29.3 \%$ for the modified blades than the results of the primary feeding rate and it was $28.5 \%$ for the modified blades with the circular saw disks.

On the other hand, and for the same feeding rate $(100 \%$ more than the primary feeding rate) the machine productivity increased about $24.1 \%$ by using the modified blades than the original blades and it increased another one $17.6 \%$ when using the modified blades with the circular disks than the modified blades. It was found also that, using the modified blades 
with the circular saw disks increased the machine productivity with about $46.1 \%$ than using the original blades as presented in Fig. 10.

Comparing the results of increasing the machine input $100 \%$ with the results of $50 \%$ increase in feeding rate, it was shown that, there was a decrease in a ratio of $18.1 \%$ for productivity than its one for the original blades.

This decrease was $10.5 \%$ for the modified blades and it was only $6.6 \%$ for the modified blades with the saw disks. The results are presented in Fig. 10.

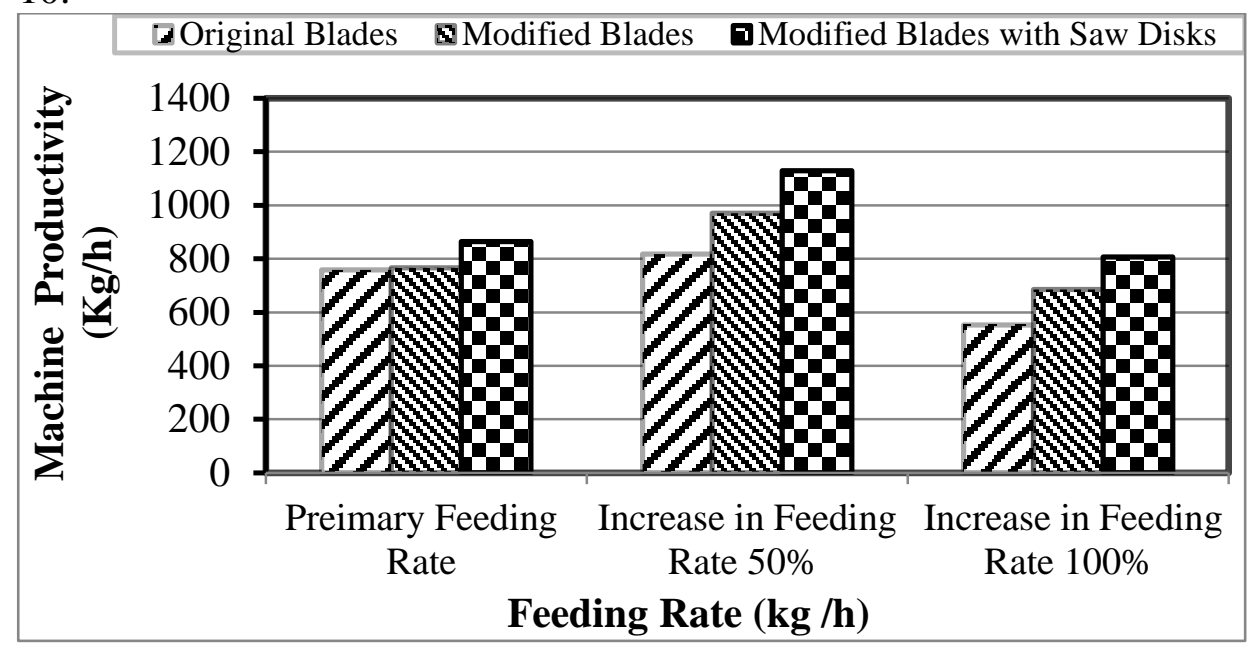

Fig. 10. The effect of the blade construction in the machine productivity

\section{2 - The Effect of the Blade Construction on the Machine Efficiency \\ 1.2 The Primary Feeding Rate}

The results presented in Fig. 11 showed that the threshing efficiency was about $89 \%$ when using the original blades. It increases to $90.5 \%$ by using the modified blades. The threshing efficiency increases $6 \%$ to reach about $96 \%$ when using the modified blades with the circular saw disks. Some loss obtained was due to some of the threshed maize goes away as dust and some other maize did not pass through the sieve. That is the reason of the efficiency difference.

\subsection{Increasing the Feeding rate $50 \%$}

Generally, there is an increase in the machine efficiency using the modified blades in every stage. The results presented in fig. 11 showed that the threshing efficiency was about $91 \%$ when using the original 
blades. It increases to $91.66 \%$ by using the modified blades. The threshing efficiency increases $5.6 \%$ to reach $96.16 \%$ when using the modified blades with the circular saw disks.

\subsection{Increasing the Feeding rate $100 \%$}

Although its results for the productivity was lower than the other feeding rate but the results of every modified stage are better than the former one. The results presented in fig. 11showed that the threshing efficiency was $84.3 \%$ when using the original blades. It increases to $91.5 \%$ by using the modified blades. The threshing efficiency reached $96.1 \%$ when using the modified blades with the circular saw disks. The machine efficiency increased about 14\% when using the modified blades with the circular saw disks than the original blades.

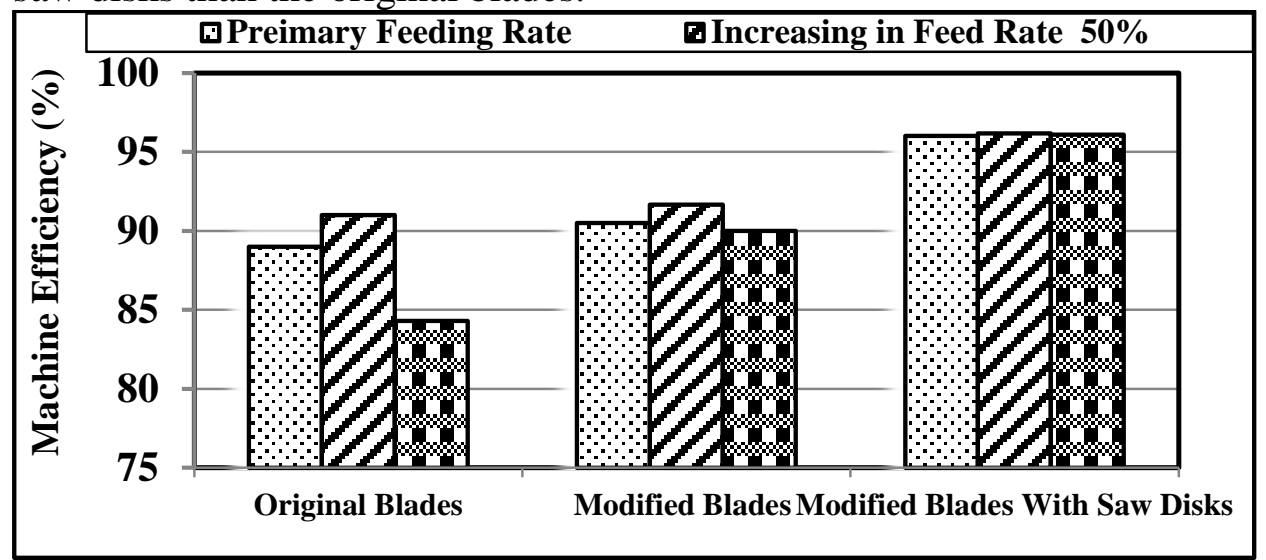

Fig.11. The effect of the blade construction in the machine efficiency

\section{3- The effect of the blade construction on the machine sound level}

According to Law 4 for year 1994 for the Environment Protection, Egyptian Ministry of Environment, the sound level must not exceed definite limits. These limits which concern us in this study can be summarized as.

$1-45 \mathrm{db}$ from 7 AM to 6 PM in the rural residential area.

2- $55 \mathrm{db}$ from $7 \mathrm{AM}$ to $6 \mathrm{PM}$ in the residential areas of the cities.

3- $65 \mathrm{db}$ from $7 \mathrm{AM}$ to $6 \mathrm{PM}$ in the residential areas of the cities.

In this work the machine sound before and after modification was measured to keep the environmental atmosphere in these workshops healthy especially babies, students, and patients can be found in these areas. 


\subsection{The Original blades operated without feeding material}

Frist of all, the sound of the machine when it works empty was measured. The results showed that the average value of the machine sound was 103 $\mathrm{db}$. This means that it is about $1.29 \%$ more than the sound level limits in the rural residential areas, about $0.87 \%$ more than the sound level limits in the residential areas of the cities, about $0.58 \%$ more than sound level limits in the residential areas of the cities where small workshops or stores and it was about $0.14 \%$ more than sound level limits in the in the workshops and factories. This huge amount of the over limits noisy is because of the clearance between the blades and the shaft. This make the blades strongly vibrated and make a lot of noisy. Another thing that rise the noisy is that, the blades at the beginning and at the end of the process collide with the shafts.

\subsection{The Modified Blades with Plastic Sleeves and the Circular Saw Disks with Primary Feeding Rate.}

The machine was initially operated after the blades modification. The sound level measured in this case recorded an average value of $92 \mathrm{db}$. It is due to the modification occurred for the blades. That mean, reducing the clearance and constructing the plastic sleeves play a vital rule in machine noise reduction. It is observed that at the beginning of the feeding process the sound level is reduced to $85 \mathrm{db}$. This is due to the noise damping occurred by the maize grains during feeding. The noise rises slowly because the milling room space becomes bigger. It average value reaches $92 \mathrm{db}$ again after milling process. This value is also over limit by a ratio of $2 \%$. That is because the blades collide with the shafts. To become more reduction in machine noise, motor noisy must also reduce.

\subsection{The Modified Blades with Plastic Sleeves and the Circular Saw Disks when increasing the Feeding Rate by $50 \%$}

As mentioned above, the machine noisy level recorded an average value of $92 \mathrm{db}$ at the beginning of the machine operation. The only different was that the noisy damping time was extended. It reduced to $85 \mathrm{db}$ at the beginning of the feeding process. This is due to the noisy damping occurred by the maize grains during feeding. The voice rises slowly because the milling room space becomes bigger. It average value reaches $92 \mathrm{db}$ again after milling process. 


\subsection{The Modified Blades with Plastic Sleeves and the Circular Saw Disks when increasing the Feeding by $100 \%$}

The same procedures were followed to test the machine noisy level when increasing the feeding rate $100 \%$. It was found also that, the machine sound level recorded an average value of $92 \mathrm{db}$ at the beginning of the machine operation. By starting the feeding process the average voice value reduced to $85 \mathrm{db}$ also. The voice damping time extended more. All the former results are presented in Fig. 12.

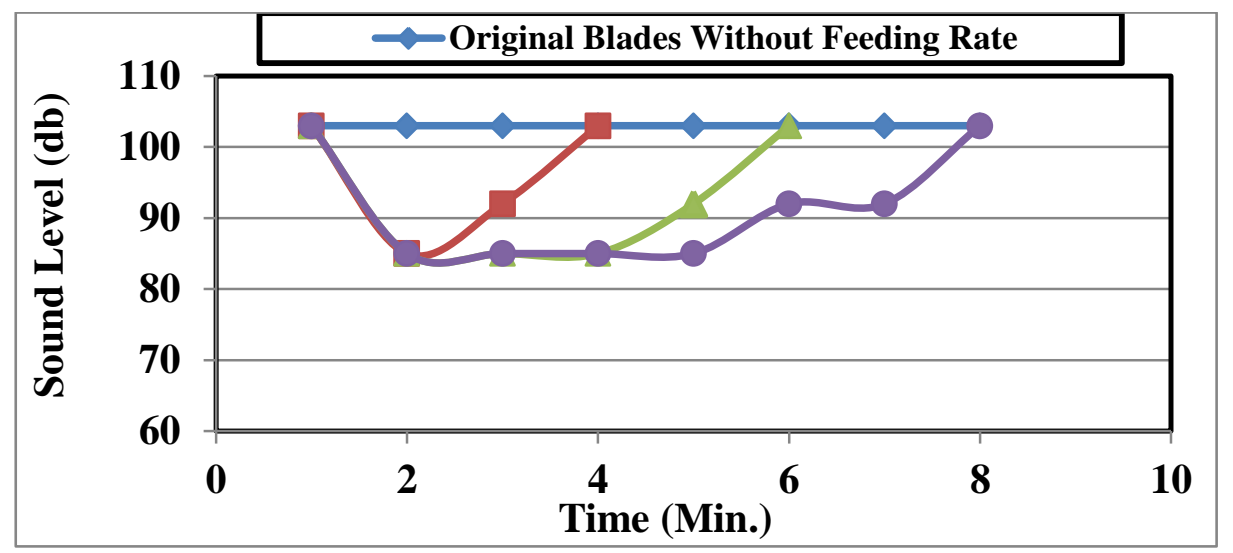

Fig . 2. The Relation between the noisy level and the blades modification

\section{CONCLUSION}

A hammer mill machine was modified to mill a wide range of farm residuals. Less or maybe there is no effort were done to improve the work environment for farm machines. The machine was modified to reduce the machine noisy through operating. As an added value to this machine it was used to mill poultry fodder. Aanother modification was done to achieve this target. The results showed that:

1- Using the modified blades with the circular saw disks increased the machine productivity than using the modified blades only than the original blade.

2- Increasing the feeding rate by $50 \%$ than the primary feeding rate increased the machine productivity with all the blades.

3- On the other hand, increasing the machine feeding rate by $100 \%$ decreased generally the machine productivity.

4- The machine efficiency increases when using the modified blades with the circular saw disks than the other kinds of blades. 
5- The modified blades with the circular saw disks reduced the noisy level than the other blades kinds.

\section{REFERENCES}

Abd El-Mottaleb, A. F. and A.R. Obaia (2006). Study on manufacture of animal fodder from date palm leaves. J. Agric. Sci. Mansoura U. 31 (7): 163-175 Adekomaya S. O. and O.D.Samuel (2014) Design and Development of a Patrol Powered Hammer Mill for rural Nigeria Farms. Journal of Energy. Technologies and Policy. Vol. 4 No. 4, 2014.

Ajaka E. O. and Adesina A. (2014) Design and Fabrication and Testing of A Laboratory Size Hammer Mill. International Journal of Engineering and Advance Technology Studies. Vol2, pp. 11-21, June 2014.

EEAA. (1994). Egyptian Environmental Affairs Agency. Law 4 for the Protection of the Environment Amended by Law 9/2009.

Egela, M.I.; Y.F. Sharobeen ; and M.E. Badawy (2003) : Modification of some operational parameters for a local manufactured hammer mill. The 11th Ann. Conference of the Misr Soc. of Ag. Eng. , 1516 Oct., 830-840.

El Shal ,M.S., M.A. Tawfik, A.M. El Shal and K. A. Metwally (2010) Study the effect of some operational factors on Hammer Mill. Misr J. Ag. Eng., 27(1): $54-74$.

Hegazy, K.E.S., A.O. El-Ashhab, B.A. Hemeda and Mosa, M.A. Magda (2002) Preparation and conversion of eggshell as hatchery by-product wastes to produce untraditional poultry feeds. Misr. J. Ag. Eng., 19 (2): 958-972.

Hegazy K.E. (2006): Development and evaluation a locally made grain crusher to suit production of livestock feeds from date pits. J. Agric. Sci. Mansoura U., 31.

Jihoe K., C. Heechen, L. Daeyang and K. Rine. (2014) investigation of breakage charachtrestics of low rank coals in laboratory swing hammer mill. Power Technology 256 (2014) 377- 384. 
Tingshuang G., M. Sánchez and G. Pei Yu (2002) "Animal production based on crop residues processing machines" - Chinese Experiences. Food and Agriculture Organization of the United Nations (FAO), Viale delle Terme di Caracalla, 00100 Rome, Italy.

Yousef, I.S. (2005) "A study on performance improvement of the local manufactured hammer mill used in polity forms". J. Agric., Sci. Mansoura Univ., 2 (11): 6827-6840.

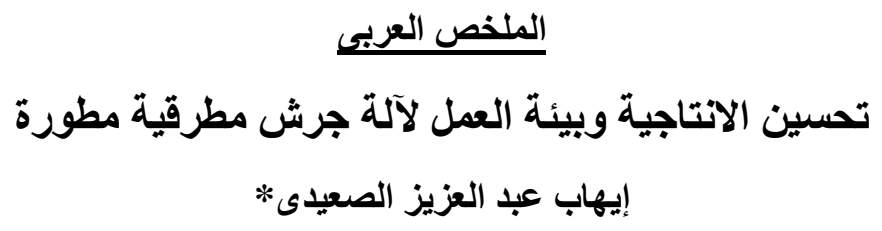

تم تطوير آلة فرم مطرقية لتستخدم على نطاق و اسع من المخلفات الزر اعية. و هنالك القليل اوربما

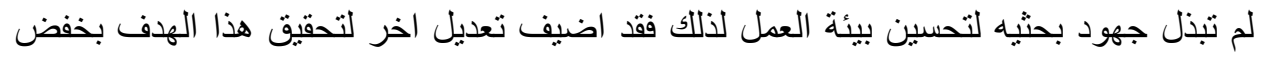
الضوضاء الصادرة من الماكينه أثناء التشغيل وكقيمة مضافة لهذ الماكينة تم استخدمها لطحن

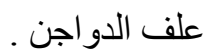

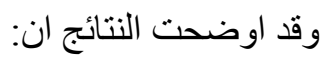

1- استخدام الاسلحة المعدلة مع الاقراص الدائرية زاد من انتاجية الماكينة عن استخدام

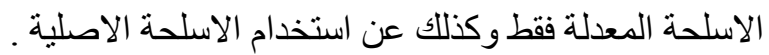

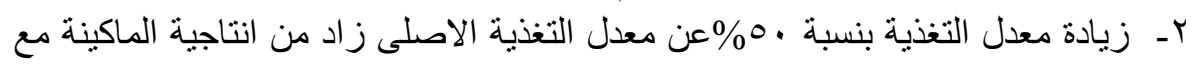
جميع انواع الاسلحة. ץ- و على الجانب الاخر فزيادة معدل التغذية بنسبة . . 1\% قلل من انتاجية الماكينة عاما

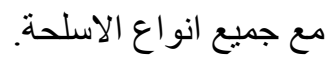
ع- - زادت كفاءة الماكينة عند استخدام الاسلحة المعدلة مع الاقر اص الدائرية عن باقى انواع هـ استخدام الاسلحة المعدلة مع الاقراص الدائرية قلل من مستوي الصوت عن باقى انواع الاسلحة. 